\title{
THE 3rd AFIR INTERNATIONAL COLLOQUIUM
}

Rome, the Eternal City, was the scene for the 3rd AFIR International Colloquium, which took place there from 30 March to 2 April 1993. In such a location, the quandary of those who wondered whether to explore the classical antiquities, the churches of all ages, the innumerable art galleries, or just the space and peace of the Borghese Gardens nearby as an alternative to the Scientific Sessions, was understandable.

The hospitality and enthusiasm of our Italian hosts was overwhelming. A few Italians, indeed, were so enthusiastic to carry their visitors' luggage that they refrained from saying where they were carrying it to; but even that could be overlooked in the city of la dolce vita.

Each of the visitors will have taken home their own special memories. Many of the accompanying persons found the visit to Assisi most memorable. For me, the two special events were the flagwaving display at the Castello Odescalchi, where the closing dinner took place, and the concert in the Palazzo della Cancelleria, which Scots would be interested to know had been the home of Henry Stuart, Cardinal of York, the younger brother of Prince Charles Edward Stuart.

But the purpose of our visit to Rome was not to see the sights and be royally entertained, but to study the subject matter pertaining to "actuaries of the third kind". The previous colloquia, in Paris in 1990 and in Brighton in 1991, were organised differently from each other, and the Rome Colloquium in the Excelsior Hotel was yet again different. Authors were each given a few minutes to present their papers, and there was then general discussion of each group of papers. But this meant rather little discussion of each individual paper. The British, who perhaps enjoy questioning each other's work, are organising a single day seminar in London in November, at which the British papers presented to the Colloquium will be discussed again.

The three largest groups of participants were from Italy, France and the United Kingdom, and the most numerous papers came also from those countries; 17 from the United Kingdom, eight each from France and Italy. It is a generalisation, but I felt that one could characterise the British (and some American) papers as being written by practitioners who had problems for which they were seeking solutions. Those from Italy were contributed generally by university professors, who had theoretical solutions and were looking for practical problems to apply them to. Those from French authors seemed to reconcile the two, demonstrating sound mathematics applied to practical problems; does the fact that many of the French authors work for banks who are in the thick of market making, rather than insurance companies, have any bearing on this?

Besides discussion of the 59 papers, there were five invited lectures. Six had been planned, but one of the proposed speakers had just been appointed to a 
high position in President Clinton's administration; this shows the Committee's good judgement in selecting the best. Fortunately Phelim Boyle and Hans Bühlmann and the three Italian speakers, Professors Pressacco, de Felice and Moriconi had not been elevated out of our sight.

The content of an hour's lecture on a mathematical subject is often best appreciated when the printed version is studied again at leisure later. The Italian organisers propose that the text of all five lectures will be published. In particular I shall find Professor Moriconi's work on "Analysing default-free bond markets by diffusion models", in which he separated out a yield curve for "real" interest rates, a yield curve for nominal interest rates, and a "yield curve" for prospective inflation, worthy of careful further study, particularly in connection with British index-linked stocks.

Phelim Boyle gave a most elegant and simple explanation of risk-neutral probabilities, which I hope will become widely copied. And Hans Bühlmann discussed, inter alia, the apparent paradox that, when investment returns are stochastic, the expected value of a unit at the end of one period is not equal to the present value of the expected return. In symbols: $E[1 /(1+i)] \neq 1 / E[1+i]$.

With certainty, the normal actuarial relationship that $v=1 /(1+i)$ holds. But to give a specific stochastic example, if $1+i$ is lognormally distributed, $E[1+i]=\exp \left(\mu+\sigma^{2} / 2\right)$ whereas $E[1 /(1+i)]=\exp \left(-\mu+\sigma^{2} / 2\right)$. But if we set aside now the latter quantity, then at the end of one period our expectation is not unity but is $\exp \left(\sigma^{2}\right)$. Is it not therefore correct to set aside only $\exp \left(-\mu-\sigma^{2} / 2\right)$ ?

It would be invidious to pick out a single paper as contributing the most to the sum of actuarial knowledge. All deserve careful study. Each student will find something that increases his or her understanding of the complex subject of investment mathematics and its actuarial implications, that stimulates him to further research, or that provides him with an answer, or a way to an answer, to a problem he has been seeking to solve. Colloquium papers are not just for those who attend. They remain as a record of the latest current ideas on the subject for others to study. The Transactions of the 3rd AFIR International Colloquium are worthy successors to the papers of the first two.

We look forward to the 4th International AFIR Colloquium in Orlando, 20-22 April 1994, which will no doubt differ from and be as valuable as its predecessors.

DAVID WILKIE 